\title{
Optimization of the pre-treatment of white sawdust (Triplochiton scleroxylon) by the organosolv process for the production of bioethanol
}

\author{
Thierry Tchamba Tchuidjang ${ }^{1,2}$, Eric Noubissié ${ }^{1, *}$, and Ahmed Ali ${ }^{1,2}$ \\ ${ }^{1}$ Laboratory of Chemical Engineering and Environment, University Institute of Technology (IUT), University of Ngaoundéré, \\ P.O. Box: 455, Ngaoundéré, Cameroon \\ ${ }^{2}$ Department of Process Engineering, National Advanced School of Agro-Industrial Sciences, University of Ngaoundéré, \\ P.O. Box: 455, Ngaoundéré, Cameroon
}

Received: 18 September 2020 / Accepted: 27 January 2021

\begin{abstract}
The exploitation of our forests generates waste, amongst which sawdust produces approximately cubic meter per year. The objective of this work is to contribute to the improvement of the recovery process of this waste through the optimization of the pre-treatment stage of sawdust from Ayous (Triplochiton scleroxylon) by the organosolv process in order to produce bioethanol. To achieve this objective, Ayous sawdust was sampled and then characterized, followed by the pre-treatment through organosolv process. During pretreatment, a composite experimental design centred on three factors (temperature, time, ethanol concentration) was used to study their effects on extraction of pentoses, reducing sugars and phenolic compounds. Analysis shows that Ayous sawdust contains $45.33 \pm 5.5 \%$ cellulose, $30.32 \pm 1.95 \%$ lignin and $20.03 \pm 3.5 \%$ hemicellulose. To release the maximum of pentoses, reducing sugars and the minimum of phenolic compounds, an organosolv pre-treatment of this substrate should be carried out at $209.08{ }^{\circ} \mathrm{C}$ for 47.60 min with an ethanolwater ratio of $24.02 \%$. Temperature is the factor having the most positive influence on the pre-treatment process whereas, ethanol concentration is not an essential factor. Organosolv pre-treatment is an effective process for delignification of the lignocellulosic structure of Ayous sawdust.
\end{abstract}

\section{Introduction}

Cameroon has the second largest forest in Africa, more than 18 million hectares of exploitable dense forest, representing $40 \%$ of the country's surface. About 80 different species are sold. Ayous (light white wood) and Sapelli (heavy red wood) account for a third of these commercial exports, although wood such as Mahogany, Moabi, and Azobe is also exploited [1]. Their exploitation in the industries of first and second processing generates waste like sawdust of about one million cubic meters per year [2]. Part of it is used as a fuel to replace the firewood [3] and as a fertilizer with a low yield due to its slow degradability [4]. The other part is burned, thus polluting the atmosphere [5]. In this wood processing chain in Cameroon, Ayous (Triplochiton scleroxylon) is the most abundant and most used species [1].

The world's stock of economically exploitable fossil energy (oil, gas, and coal) is limited and the number of people in the world is estimated at 7.5 billion today and

\footnotetext{
* Corresponding author: noubissieerik@yahoo.fr; eric.noubissie@univ-pau.fr
}

10 billion in 2050 [6]. In these circumstances, it would be essential to prepare the succession of the combustible fossil towards renewable forms of energy based on organic raw material. The development of second-generation biofuels based on the conversion of cellulosic biomass into bioethanol by enzymatic hydrolysis [7-9] or into biodiesel by thermochemical gasification [10] or liquefaction by catalytic conversion [11, 12].

The increase in the price of oil and the increase in greenhouse gas emissions justify the search for raw materials and alternative technologies capable of reducing dependence on these fossil fuels and protecting the environment [13]. Bioethanol is already used to substitute a fraction of the volume of gasoline in many countries [14]. Several authors have worked on the conversion of lignocellulosic biomass into bioethanol using the organosolv processes [13, 15-17], thermohydrolysis $[18,19,21]$, the acid treatment process $[20,21]$ and that of alkaline treatment [20]. It emerges from this work that the organosolv process is one of the best because it makes it possible to delignify the biomass without denaturing the other compounds, while ethanol and lignin can be recovered on the other hand $[16,17]$. But to the 
best of our knowledge, there is no work on the production of bioethanol from sawdust pre-treated by the organosolv process.

In view of the great wealth of lignocellulosic biomass (sawdust) in general and of Triplochiton scleroxylon sawdust particularly in Cameroon, it would be wise to exploit this wealth for the production of bioethanol which is already in use in several countries. The organosolv process being a recommendable pre-treatment process, we thought of optimizing it in the pre-treatment of sawdust from Ayous (Triplochiton scleroxylon) for the production of bioethanol. It will be specifically a question to study the influence of temperature, time and ethanol concentration (ethanolwater ratio) on the pre-treatment by the organosolv process. Then, it will be necessary to find an optimal range which makes it possible to maximize the pentoses and the reducing sugars, and to minimize the phenolic compounds. This work has an interest on the technological level through the optimisation of the process of transformation of cellulosic biomass in to bioethanol, on the environmental level through the management of solid waste and the project of substitution of fossil fuels by bioethanol produced.

\section{Material and methods}

\subsection{Substrate sampling and characterization}

Ayous sawdust (Triplochiton scleroxylon) was collected from a sawmill in the town of Ngaoundéré. Once in the laboratory, the sawdust underwent a physico-chemical characterization through the determination of its dry matter (MS) according to the Van Soest method [15] and its Mineral Matter (MM) according to the calcination method [22]. The lignin content was determined according to the method developed by Klason [23], the hemicellulose content according to the method of N'Diaye et al. [24] and the cellulose content according to the method of Godin et al. [25].

\subsection{Substrate pre-treatments}

Organosolv pre-treatment of sawdust is necessary to release the cellulose from the lignin-hemicellulose complex. It also makes it possible to reduce cellulosic crystallinity and makes the cellulose accessible to enzymes during the hydrolysis step. In order to better control this pre-treatment step, modelling by the response surface methodology was used. This is how the centred composite plan was used to determine the optimal levels of the various factors influencing treatment. For this purpose, the centred composite plan of the "iso-variance by rotation" type was chosen. It has the advantage of being able to appreciate what happens outside the experimental conditions.

\subsubsection{Choice of factors and experience matrix}

Temperatures are generally between $173{ }^{\circ} \mathrm{C}$ and $207{ }^{\circ} \mathrm{C}$ during organosolv pre-treatment [26]. The time interval (15-45 min) was chosen based on the work of Carrasco and Oncina [27] and Kabel et al. [28]. The ethanol concentration between $30 \%$ and $70 \% \mathrm{v} / \mathrm{v}$ was fixed under the basis of the work of Wildschut et al. [15] and Pan et al. [29]. Table 1 presents the experimental matrix for the pre-treatment of the organosolv method.

The mathematical model postulated is of the seconddegree polynomial type with interactions. Its expression is in the form of equation (1):

$$
Y=a_{0}+\sum_{i=1}^{k} a_{i} x_{i}+\sum_{i=1}^{k} a_{i i} x_{i}^{2}+\sum_{i=1}^{k} \sum_{j=1}^{k} a_{i j} x_{i} x_{j}+\varepsilon
$$

$Y=$ concentration of reducing sugars, pentoses, phenolic compounds, dependent variable (response).

$x_{i}$ and $x_{j}=$ dependent variable; $a_{0}=$ constant; $\varepsilon=$ error. $a_{i}=$ linear coefficient; $a_{\mathrm{ii}}=$ quadratic coefficient; $a_{i j}=$ interaction coefficient.

The fit quality of the model was expressed by the determination coefficients $R^{2}$ and adjusted $R^{2}$ which must be less than 80 [30]. As this mathematical tool was not sufficient to validate a model, other tools and methods were used to judge the adequate quality of the models. To this end, the Absolute Mean Deviation Analysis (AADM) between the calculated and observed values [31], the Bias factor (Bf) [32] and the Accuracy factor (Af) [32] were carried out. They were calculated from equations (2)-(4):

- Bias factor (Bf):

$$
\mathrm{Bf}=10^{B} \text { with } B=\frac{1}{n} \sum_{i=1}^{n} \log \frac{Y_{i, \text { the }}}{Y_{i, \mathrm{obs}}} .
$$

- Accuracy factor (Af):

$$
\text { Af }=10^{A} \text { with } A=\frac{1}{n} \sum_{i=1}^{n}\left|\log \frac{Y_{i, \text { the }}}{Y_{i, \mathrm{obs}}}\right| .
$$

- Absolute Mean Deviation Analysis (AADM)

$$
\mathrm{AADM}=\frac{\sum_{i=1}^{n}\left(\left|\frac{Y_{i, \mathrm{obs}}-Y_{i, \mathrm{the}}}{Y_{i, \mathrm{obs}}}\right|\right)}{n}
$$

$Y_{\text {the }}$ and $Y_{\text {obs }}$ are respectively the experimental response and calculated from the model for an experiment $i ; n$ being the total number of experiments.

\subsubsection{Pre-treatment operation}

The organosolv pre-treatment process was carried out in batch, without agitation in a stainless-steel reactor with a capacity of $150 \mathrm{~mL}$. The organosolv pre-treatment concretely consisted in introducing $3 \mathrm{~g}$ of sawdust into $75 \mathrm{~mL}$ of an ethanol solution at the concentration indicated by the experimental matrix. The whole mixture was brought to the set temperature and for the duration indicated by the experimental matrix. The treatment time was counted from the moment the set temperature was attained. The warm-up time was between 15 and $20 \mathrm{~min}$. The treatment was stopped by cooling with cold water and the liquid fraction was recovered using a filtration device. 
Table 1. Matrix of real and coded variables of the centred composite plane of organosolv pre-treatment.

\begin{tabular}{|c|c|c|c|c|c|c|}
\hline \multirow[t]{2}{*}{ Experience } & \multicolumn{3}{|c|}{ Coded variables } & \multicolumn{3}{|c|}{ Real variables } \\
\hline & Temperature & Time & $\begin{array}{c}\text { Concentration } \\
\text { of ethanol }\end{array}$ & $\begin{array}{c}\text { Temperature } \\
\left({ }^{\circ} \mathrm{C}\right)\end{array}$ & $\begin{array}{l}\text { Time } \\
(\min )\end{array}$ & $\begin{array}{l}\text { Concentration of } \\
\text { ethanol }(50 \% \mathrm{v} / \mathrm{v})\end{array}$ \\
\hline 1 & 0 & 0 & 0 & 190 & 35 & 50 \\
\hline 2 & 0 & 0 & 0 & 190 & 35 & 50 \\
\hline 3 & 0 & 0 & 0 & 190 & 35 & 50 \\
\hline 4 & 0 & 0 & 0 & 190 & 35 & 50 \\
\hline 5 & -1 & -1 & -1 & 190 & 20 & 30 \\
\hline 6 & 1 & -1 & -1 & 210 & 20 & 30 \\
\hline 7 & -1 & 1 & -1 & 170 & 50 & 30 \\
\hline 8 & 1 & 1 & -1 & 210 & 50 & 30 \\
\hline 9 & -1 & -1 & 1 & 170 & 20 & 70 \\
\hline 10 & 1 & -1 & 1 & 210 & 20 & 70 \\
\hline 11 & -1 & 1 & 1 & 170 & 50 & 70 \\
\hline 12 & 1 & 1 & 1 & 210 & 50 & 70 \\
\hline 13 & 1.41 & 0 & 0 & 218.2 & 35 & 50 \\
\hline 14 & -1.41 & 0 & 0 & 161.8 & 35 & 50 \\
\hline 15 & 0 & 1.41 & 0 & 161.8 & 56.15 & 50 \\
\hline 16 & 0 & -1.41 & 0 & 190 & 13.85 & 50 \\
\hline 17 & 0 & 0 & 1.41 & 190 & 35 & 78.2 \\
\hline 18 & 0 & 0 & -1.41 & 190 & 35 & 21.8 \\
\hline
\end{tabular}

\subsubsection{Characterization of the pre-treated substrate}

The content of reducing sugars was determined by the colorimetric method of Fisher and Stein [33]. Total phenolic compounds were determined by the Folin-Ciocalteu method [34] with some modifications. The pentose content of the pre-treatment hydrolysates was determined by the method of Hashimoto et al. [35].

\subsection{Optimization}

The optimization which consisted in seeking the optimal conditions allowing to have the maximum of reducing sugars and pentoses, as well as the minimum of phenolic compounds was carried out by the software Minitap 17 .

\section{Results}

Ayous sawdust contains $45 \pm 6 \%$ cellulose, $30 \pm 2 \%$ lignin and $20 \pm 3 \%$ hemicellulose. The other characteristics of Ayous sawdust are recorded in Table S1 of the Supplementary Material.

\subsection{Mathematical models of the different experimental responses}

The experimental design responses are presented in Table 2.

Three second-degree polynomial mathematical models describing the extraction of the different responses during the organosolv pre-treatment of sawdust from Ayous were generated by this centred composite plane. The content of pentoses $\left(Y_{\mathrm{P}}\right)$ materialized by equation $(5)$ is a measure which reflects the solubilization rate of the hemi cellulosic fraction. The content of reducing sugars $\left(Y_{\mathrm{RS}}\right)$ materialized by equation (6) reflects the solubilization of celluloses and the content of phenolic compound $\left(Y_{\mathrm{PC}}\right)$ materialized by equation (7) reflects the solubilisation of lignin. The validation indicators for these three mathematical models are presented in Table 3:

$$
\begin{aligned}
Y_{\mathrm{P}}= & 2.925+0.338 X_{1}-0.337 X_{2}-0.227 X_{3} \\
& -0.094 X_{1}^{2}-0.248 X_{2}^{2}+0.969 X_{3}^{2} \\
& +0.263 X_{1} X_{2}-0.564 X_{1} X_{3}+0.270 X_{2} X_{3},
\end{aligned}
$$

$$
\begin{aligned}
Y_{\mathrm{RS}}= & 2.049+0.2062 X_{1}+0.4094 X_{2}+0.1901 X_{3} \\
& -0.1747 X_{1}^{2}+0.4271 X_{2}^{2}-0.1611 X_{3}^{2} \\
& +0.0440 X_{1} X_{2}-0.1546 X_{1} X_{3}-0.1952 X_{2} X_{3}, \\
Y_{\mathrm{PC}}= & 21.11+13.17 X_{1}+26.55 X_{2}+11.12 X_{3} \\
& +4.01 X_{1}^{2}+14.10 X_{2}^{2}+3.36 X_{3}^{2}-1.25 X_{1} X_{2} \\
& +3.54 X_{1} X_{3}+3.11 X_{2} X_{3} .
\end{aligned}
$$

The three mathematical models are valid under the basis of the intervals provided by the validation criteria presented in Table 3. The significance at the $95 \%$ threshold of the different effects expressed by each factor and the interactions on the different responses are presented in Table 4. 
Table 2. Experimental and calculated responses of the centred composite plan of the organosolv pre-treatment of sawdust from Ayous.

\begin{tabular}{|c|c|c|c|c|c|c|c|c|c|}
\hline & \multicolumn{3}{|c|}{ Real variables } & \multicolumn{2}{|c|}{ Pentose $(\mathrm{mg} / \mathrm{mL})$} & \multicolumn{2}{|c|}{$\mathrm{RS}(\mathrm{mg} / \mathrm{mL})$} & \multicolumn{2}{|c|}{$\mathrm{PC}(\mu \mathrm{g} / \mathrm{mL})$} \\
\hline & $X_{1}$ & $X_{2}$ & $X_{3}$ & $Y_{\mathrm{ExpP}}$ & $Y_{\text {CalP }}$ & $Y_{\text {ExpRS }}$ & $Y_{\text {CalRS }}$ & $Y_{\mathrm{ExpPC}}$ & $Y_{\text {CalPC }}$ \\
\hline 1 & 190 & 35 & 50 & 3.750 & 2.925 & 0.094 & 2.049 & 20.177 & 21.106 \\
\hline 2 & 190 & 35 & 50 & 2.700 & 2.925 & 0.067 & 2.049 & 19.592 & 21.106 \\
\hline 3 & 190 & 35 & 50 & 2.938 & 2.925 & 0.073 & 2.049 & 24.788 & 21.106 \\
\hline 4 & 190 & 35 & 50 & 3.869 & 2.925 & 0.097 & 2.049 & 19.584 & 21.106 \\
\hline 5 & 190 & 20 & 30 & 4.450 & 3.747 & 0.111 & 1.029 & 8,329 & 0 \\
\hline 6 & 210 & 20 & 30 & 5.080 & 5.024 & 0.127 & 1.662 & 14.982 & 18.898 \\
\hline 7 & 170 & 50 & 30 & 2.045 & 2.007 & 0.051 & 2.150 & 42.206 & 46.503 \\
\hline 8 & 210 & 50 & 30 & 4.641 & 4.337 & 0.116 & 2.960 & 67.032 & 63.277 \\
\hline 9 & 170 & 20 & 70 & 2.356 & 3.881 & 0.059 & 2.109 & 2.175 & 6.068 \\
\hline 10 & 210 & 20 & 70 & 2.942 & 2.902 & 0.074 & 2.124 & 46.151 & 41.992 \\
\hline 11 & 170 & 50 & 70 & 3.642 & 3.219 & 0.091 & 2.449 & 71.651 & 67.873 \\
\hline 12 & 210 & 50 & 70 & 2.668 & 3.293 & 0.067 & 2.640 & 87.493 & 98.817 \\
\hline 13 & 218.2 & 35 & 50 & 3.407 & 3.214 & 0.085 & 1.992 & 52.791 & 47.652 \\
\hline 14 & 161.8 & 35 & 50 & 1.911 & 2.261 & 0.048 & 1.411 & 5.639 & 10.500 \\
\hline 15 & 161.8 & 56.15 & 50 & 2.173 & 1.955 & 0.054 & 3.475 & 92.250 & 86.571 \\
\hline 16 & 190 & 13.85 & 50 & 2.232 & 2.906 & 0.056 & 2.321 & 6.309 & 11.710 \\
\hline 17 & 190 & 35 & 78.2 & 5.122 & 4.531 & 0.128 & 1.997 & 48.557 & 43.450 \\
\hline 18 & 190 & 35 & 21.8 & 4.424 & 5.172 & 0.111 & 1.461 & 7.275 & 12.103 \\
\hline
\end{tabular}

$X_{1}=$ temperature; $X_{2}=$ time; $X_{3}=$ ratio ethanol-water; $Y_{\exp }=$ experimental response; $Y_{\text {cal }}=$ calculated response $\mathrm{RS}=$ Reducing Sugars; PC $=$ Phenolic Compounds.

Table 3. Validation indicators for mathematical models expressing pentoses, reducing sugars and phenolic compounds derived from the pre-treatment of Ayous sawdust by the organosolv process.

\begin{tabular}{lccc}
\hline $\begin{array}{l}\text { Validation } \\
\text { indicator }\end{array}$ & $Y_{\mathrm{P}}$ & $Y_{\mathrm{RS}}$ & $Y_{\mathrm{PC}}$ \\
\hline$R^{2}$ & $86.17 \%$ & $92.82 \%$ & $96.36 \%$ \\
Adjusted $R^{2}$ & $70.60 \%$ & $84.74 \%$ & $92.27 \%$ \\
AADM & 0.15 & 0.06 & 0.25 \\
Bias factor & 1.00 & 1 & 1.09 \\
Accuracy factor & 1.06 & 1.03 & 1.13 \\
\hline
\end{tabular}

$Y_{\mathrm{p}}=$ content of pentoses; $Y_{\mathrm{RS}}=$ content of Reducing Sugars; $Y_{\mathrm{PC}}=$ content of Phenolic Compound.

\subsubsection{Pentoses}

Figure 1 specifies the direct effects of each factor on the extraction of pentoses during pre-treatment of Ayous sawdust. Figure 2 shows the response of the pentose extraction as a function of factors taken two by two.

It appears from Figure 1 that the increase in temperature contributes to increasing the extraction of the pentoses while the pre-treatment time contributes to decreasing the extraction of the pentoses when the operation exceeds 35 min (Tab. 3). Figure 1 also shows that there is a range of values within which the $\mathrm{E}-\mathrm{W}$ ratio is not at all favourable for the extraction of pentoses. This observation is even more perceptible on the response surfaces of Figures 2a and $2 \mathrm{~b}$ through the curvature in blue. Figure 2 shows that the temperature is the most important factor for the extraction of pentoses during the organosolv pre-treatment of sawdust from Ayous. This factor is followed by the pre-treatment time and the $\mathrm{E}-\mathrm{W}$ ratio respectively. This order of importance is visible in Figure 2c, where it can be perfectly observed that it is easier to extract the pentoses by neglecting the factor $\mathrm{E}-\mathrm{W}$ ratio, rather than neglecting the pre-treatment time. However, the quantitative yield of pentose extraction would be lower in this condition (Fig. 2c) compared to the other (Fig. 2b). 
Table 4. Meaning of the different effects of mathematical models.

\begin{tabular}{|c|c|c|c|c|c|c|}
\hline & \multicolumn{2}{|c|}{ Pentoses } & \multicolumn{2}{|c|}{ Reducing sugars } & \multicolumn{2}{|c|}{ Phenolic compound } \\
\hline & Coefficient & $P$-value & Coefficient & $P$-value & Coefficient & $P$-value \\
\hline$X_{1}$ & 0.477 & 0.066 & 0.2908 & 0.014 & 18.58 & 0.001 \\
\hline$X_{2}$ & -0.475 & 0.066 & 0.5772 & 0.000 & 37.43 & 0.000 \\
\hline$X_{3}$ & -0.320 & 0.190 & 0.2681 & 0.020 & 15.67 & 0.001 \\
\hline$X_{1}^{2}$ & -0.187 & 0.643 & -0.347 & 0.062 & 7.97 & 0.202 \\
\hline$X_{2}^{2}$ & -0.494 & 0.238 & 0.849 & 0.001 & 28.03 & 0.001 \\
\hline$X_{3}^{2}$ & 1.927 & 0.001 & -0.320 & 0.081 & 6.67 & 0.278 \\
\hline$X_{1} X_{2}$ & 0.523 & 0.212 & 0.088 & 0.599 & -2.48 & 0.676 \\
\hline$X_{1} X_{3}$ & -1.122 & 0.020 & -0.307 & 0.091 & 7.04 & 0.252 \\
\hline$X_{2} X_{3}$ & 0.536 & 0.202 & -0.388 & 0.041 & 6.19 & 0.310 \\
\hline
\end{tabular}

$X_{1}=$ temperature; $X_{2}=$ time; $X_{3}=$ ratio ethanol-water; Effects with a probability of less than 0.05 are significant at the $95 \%$ confidence level. Overall, it can be seen from this table that the direct effect of each of the three factors $\left(X_{1}, X_{2}, X_{3}\right)$, as well as the quadratic effect of the pre-treatment time $\left(X_{2}^{2}\right)$, significantly influence $95 \%$ and positively on the production of Reducing Sugars (RS) and Phenolic Compounds (PC). Which is quite the opposite with regard to the production of Pentoses. Moreover, only the quadratic effect of the ethanol-water ratio $\left(X_{3}^{2}\right)$ positively and significantly $95 \%$ affects the extraction of pentoses. Each response is presented individually in the following sections.

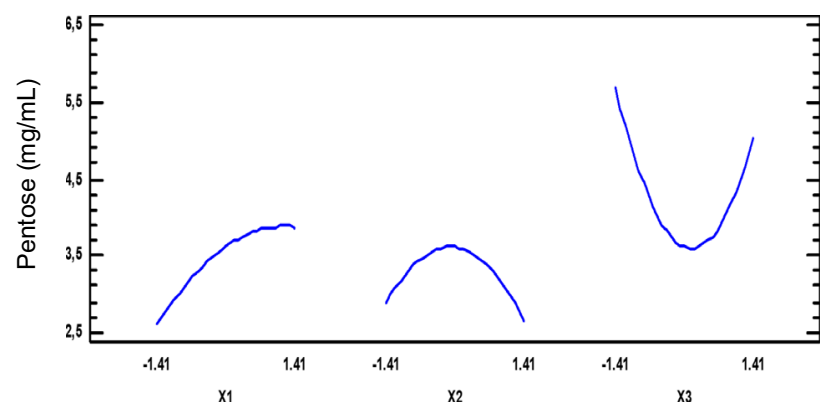

$\mathrm{X}_{1}=$ temperature; $\mathrm{X}_{2}=$ time; $\mathrm{X}_{3}=$ ratio ethanol-water

Fig. 1. Direct effects of factors on the extraction of pentoses during pre-treatment of Ayous sawdust by the organosolv method.

\subsubsection{Reducing sugars}

Figure 3 specifies the direct effects of each factor on the release of Reducing Sugars (RS) during pre-treatment of Ayous sawdust. Figure 4 shows the response of the RS extraction as a function of factors taken two by two.

Figure 3 also reveals that an increase in temperature contributes favourably and significantly to $95 \%$ in the extraction of RS whereas the time leads to a decrease of the extraction of RS when the pre-treatment operation exceeds $35 \mathrm{~min}$. There is also a range of values within which the $\mathrm{E}-\mathrm{W}$ ratio does not have a favourable effect on the extraction of RS (21\%-50\%). However, it can be seen in Figure 4 a range of values within which the $\mathrm{E}-\mathrm{W}$ ratio favours an optimal extraction of the RS, in co-operation with the temperature (Fig. 4a) and the time (Fig. 4b). But overall, it appears from Figure 5 that temperature is a factor whose increase has the most favourable influence on the extraction of RS, which makes it the most important factor for this response during the pre-treatment of Ayous sawdust. This factor is followed respectively by the pretreatment time and the $\mathrm{E}-\mathrm{W}$ ratio.

\subsubsection{Phenolic compounds}

Figure 5 specifies the direct effects of each factor on the extraction of Phenolic Compounds (PC) during pre-treatment of sawdust. Figure 6 shows the response of PC extraction according to factors taken two by two.

Figure 5 shows that an increase in each of the three factors in the reactor contributes favourably to the extraction of Phenolic Compounds (PC). This is moreover confirmed with the response surfaces on which we observe that the highest amounts of PC are obtained when the direct effect of each factor is as high as possible (Fig. 6).

\subsection{Optimal pre-treatment points}

\subsubsection{Optimal points for the extraction of pentoses}

The optimal points obtained using Minitab version 2017, for the mathematical model whose answer is the extraction of pentoses gives in coded variables are 1.4, -0.69 and -1.41 for the temperature, the pre-treatment time and the $\mathrm{E}-\mathrm{W}$ ratio, respectively. In real values, these optimal points correspond to $218.2{ }^{\circ} \mathrm{C}, 24.65 \mathrm{~min}$ and $21.8 \%$ ethanol. Under these conditions, the maximum pentose expected is $6.70 \mathrm{mg} / \mathrm{mL}$. However, the implementation of these optimal values in the pre-treatment test gives a maximum of pentoses evaluated at $7.09 \pm 0.8 \mathrm{mg} / \mathrm{mL}$, which is not significantly different (at the $95 \%$ threshold) from the expected value $(6.70 \mathrm{mg} / \mathrm{mL})$. 
(a) Temperature $=0$

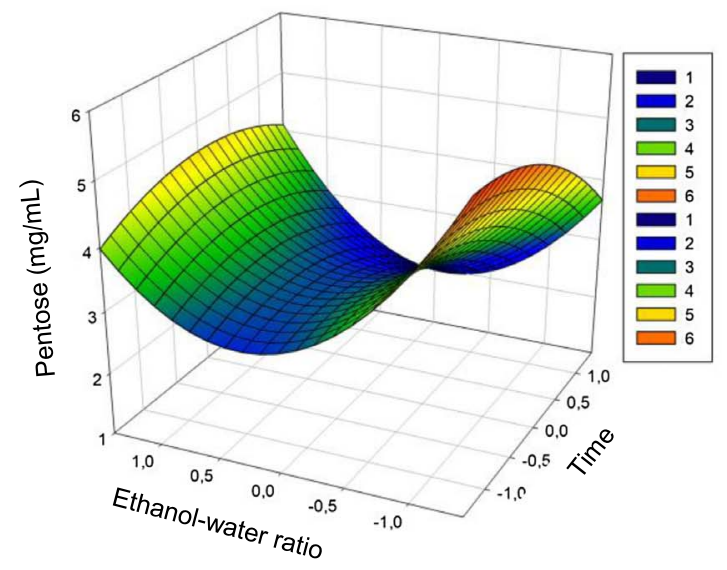

(b) Time $=0$

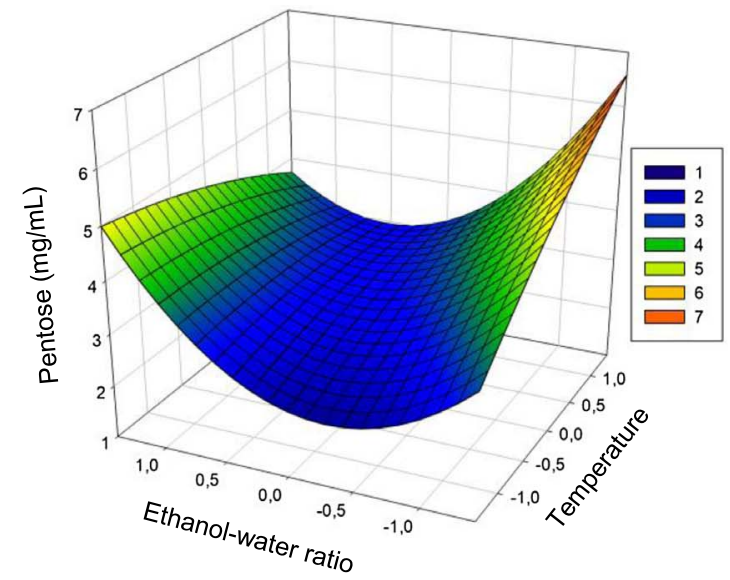

(c) Ethanol- water $(\mathrm{E}-\mathrm{W})$ ratio $=0$

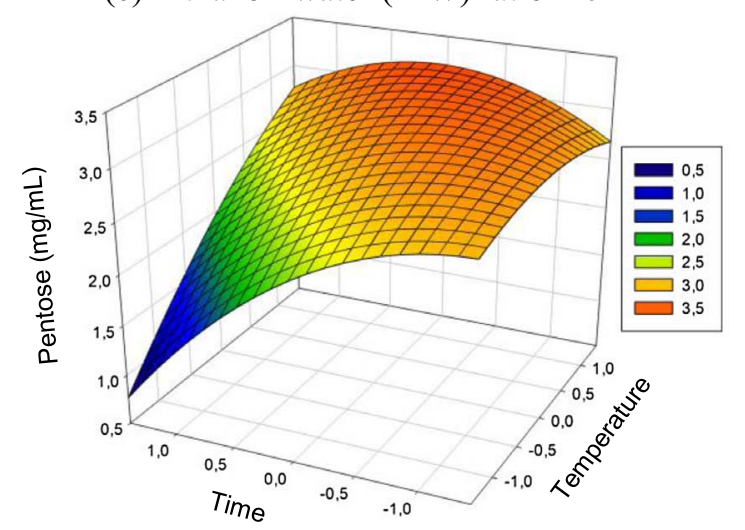

Fig. 2. Areas of response of pentose extraction as a function of time and $\mathrm{E}-\mathrm{W}$ ratio (a), temperature and $\mathrm{E}-\mathrm{W}$ ratio (b), time and temperature (c).

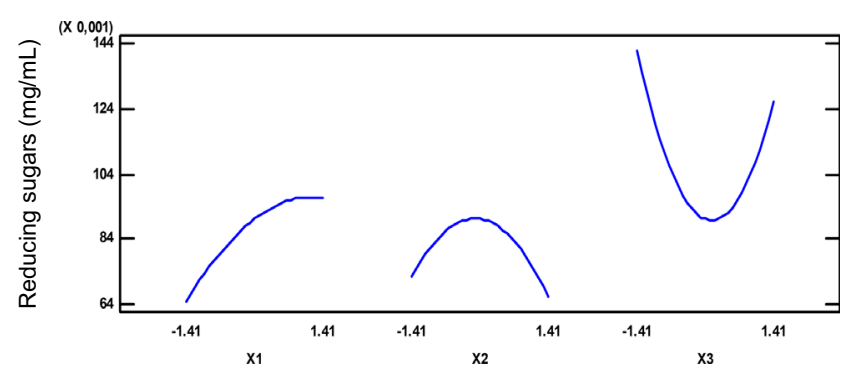

$\mathrm{X}_{1}=$ temperature; $\mathrm{X}_{2}=$ time; $\mathrm{X}_{3}=$ ethanol-water ratio

Fig. 3. Direct effects of each factor on the extraction of reducing sugars during pre-treatment of Ayous sawdust by the organosolv method. $X_{1}=$ temperature; $X_{2}=$ time; $X_{3}=$ ethanol-water ratio.

\subsubsection{Optimal points for the extraction of reducing sugars}

The theoretical optimum obtained by Minitab 2017 version in coded variables are $1.12,1.41$ and -0.81 for temperature, pre-treatment time and $\mathrm{E}-\mathrm{W}$ ratio, respectively. In real values, these optimal points correspond to $206.24{ }^{\circ} \mathrm{C}$, $56.15 \mathrm{~min}$ and $33.19 \%$ ethanol, for a maximum of Reducing Sugars (RS) expected and evaluated at $3.66 \mathrm{mg} / \mathrm{mL}$. The implementation of these optimal points in the pre-treatment test gave a maximum of $\mathrm{RS}$ evaluated at $4.09 \pm 0.8 \mathrm{mg} / \mathrm{mL}$, which is very close to the expected theoretical optimal value $(3.66 \mathrm{mg} / \mathrm{mL})$.

\subsubsection{Optimal points for the extraction of phenolic compounds}

Theoretically, the optimal points for obtaining an optimum of Phenolic Compounds (PC) in coded variables are -1.41 , -1.41 and -1.41 corresponding to temperature, pre-treatment time and $\mathrm{E}-\mathrm{W}$ ratio, respectively. In real values, these variables correspond to $161.8^{\circ} \mathrm{C} ; 13.8 \mathrm{~min}$ and $21.8 \%$ ethanol. Under these operating conditions, the target value for $\mathrm{PC}$ is $52 \mu \mathrm{g} / \mathrm{mL}$. The implementation of these optimal points in the pre-treatment test allowed to have an optimum of $49 \pm 0.8 \mu \mathrm{g} / \mathrm{mL}$. This maximum value in $\mathrm{PC}$ is satisfactory so far as it is less than the target theoretical value. 
(a) Temperature $=0$

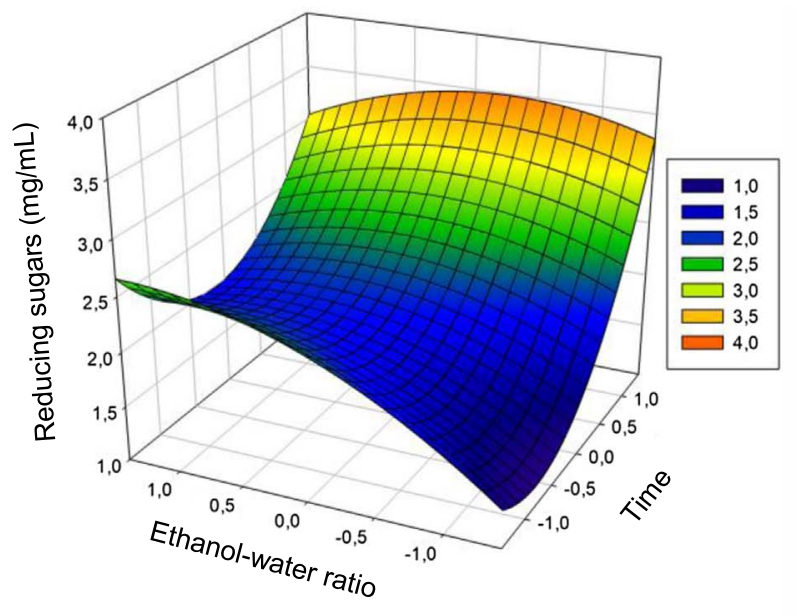

(b) Time $=0$

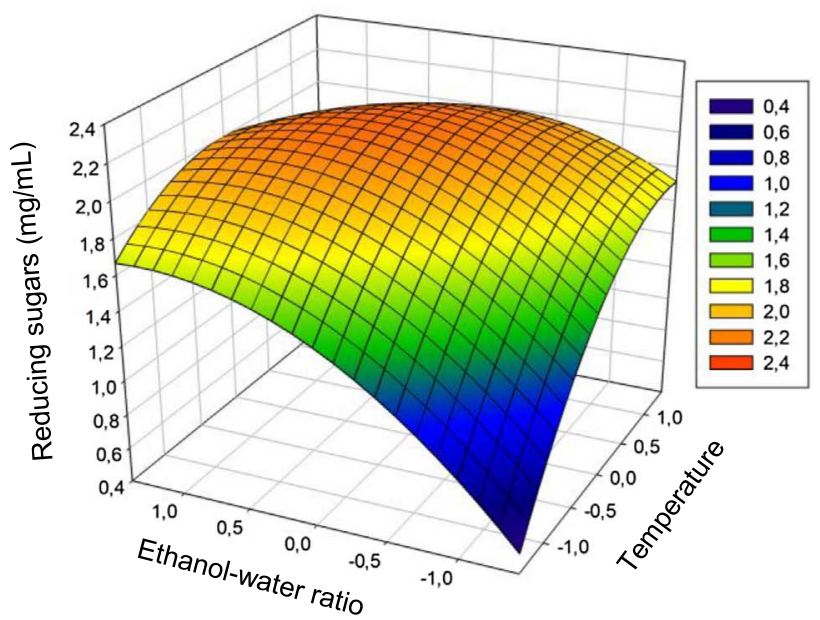

(c) Ethanol-water $(\mathrm{E}-\mathrm{W})$ ratio $=0$

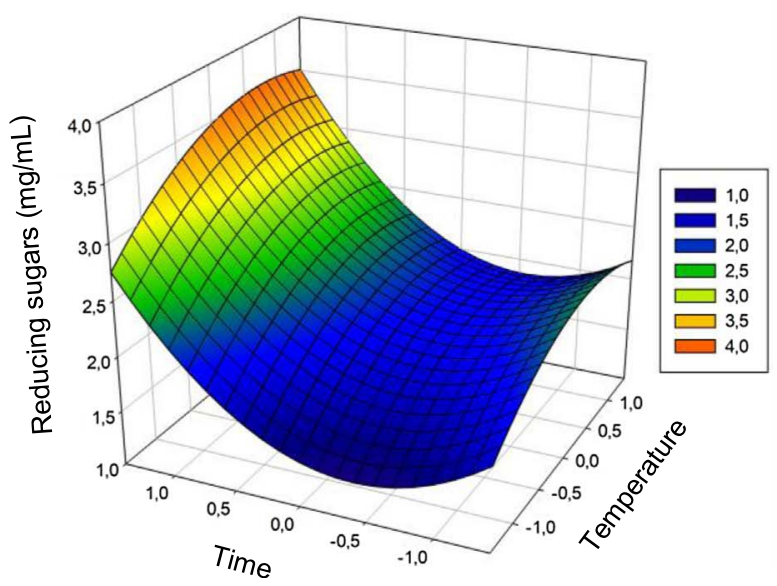

Fig. 4. Response surfaces of the extraction of reducing sugars as a function of time and $\mathrm{E}-\mathrm{W}$ ratio (a), temperature and $\mathrm{E}-\mathrm{W}$ ratio (b), temperature and time (c).

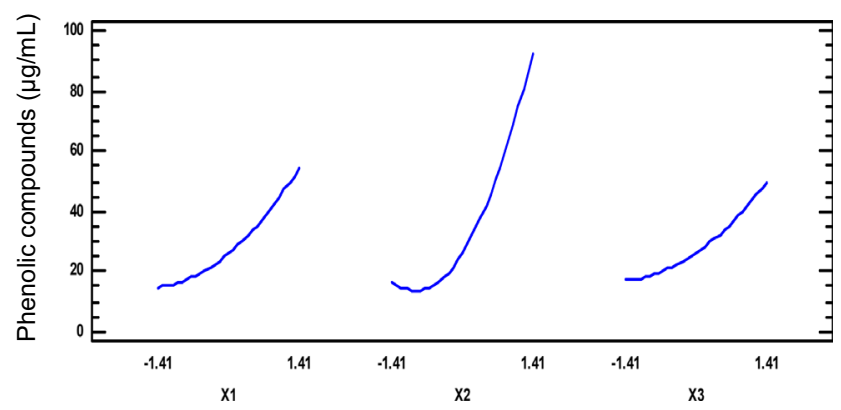

$\mathrm{X}_{1}=$ temperature; $\mathrm{X}_{2}=$ time; $\mathrm{X}_{3}=$ ethanol-water ratio

Fig. 5. Direct effects of each factor on the extraction of phenolic compounds during the pre-treatment of Ayous sawdust by the organosolv method.

\subsubsection{Optimal multi-response points}

The main objectives being to maximize the extractions of pentoses and reducing sugars and minimize that of phenolic compounds, it is necessary to find a range where these three objectives will be optimal. A multi-response optimization was performed on Minitab version 2017. Table 5 presents the optimal points for the three responses while Figure 7 shows the optimal zone for the two factors best promoting the achievement of the objectives set (temperature and time).

The black dot observed in Figure 7 indicates the optimal points for the two important factors. The values of the factors corresponding to this point will make it possible to perform a pre-treatment of sawdust from Ayous by the organosolv method with optimal extractions expected in pentoses of $5.12 \mathrm{mg} / \mathrm{mL}$, in reducing sugars of 
(a) Temperature $=0$

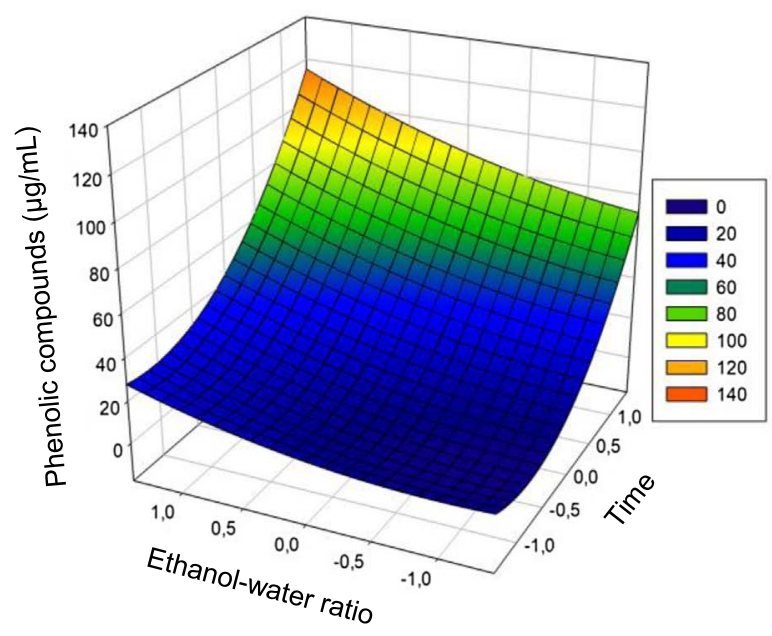

(b) Time $=0$

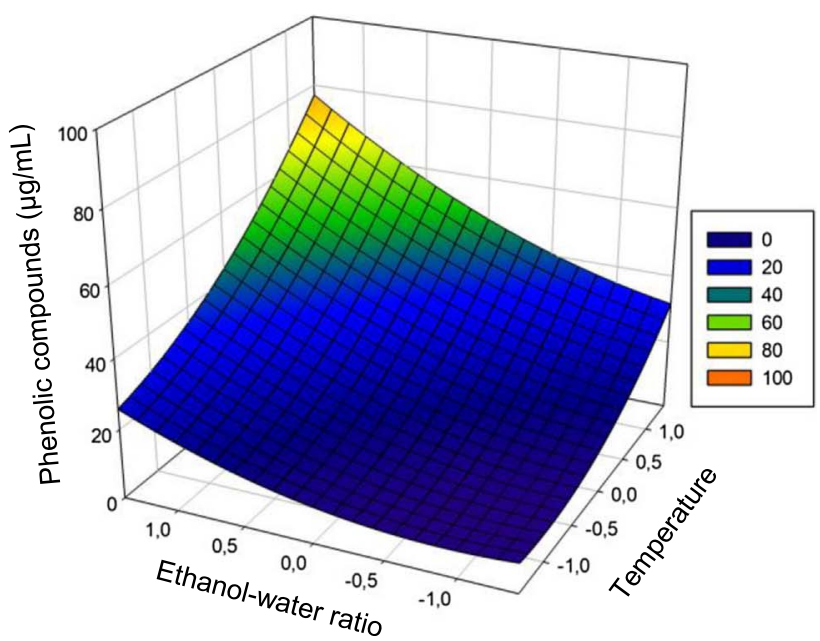

(c) Ethanol-water $(\mathrm{E}-\mathrm{W})$ ratio $=0$

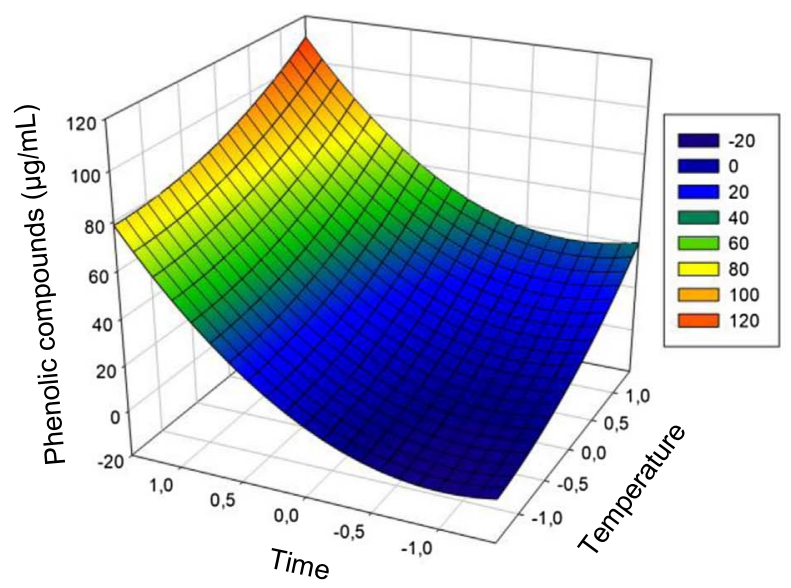

Fig. 6. Response surfaces of the extraction of phenolic compounds as a function of time and E-W ratio (a), temperature and E-W ratio (b), temperature and time (c).

$2.29 \mathrm{mg} / \mathrm{mL}$ and a minimum expected extraction of phenolic compounds of $48.77 \mu \mathrm{g} / \mathrm{mL}$.

\section{Discussion}

\subsection{Effect of factors on the effectiveness of pre-treatment}

\subsubsection{Effect of factors on the extraction of pentoses and reducing sugars}

One of the objectives of this work was to find the conditions favourable for the optimal extraction of pentoses and Reducing Sugars (RS) contained in the sawdust from Ayous during its pre-treatment by the organosolv method. Analysis of the different mathematical models having as responses the extraction of pentoses and RS shows that the temperature is the most important factor during this
Table 5. Optimal multi-response points.

\begin{tabular}{lcc}
\hline Factor & Optimum & Real values \\
\hline Temperature $\left(X_{1}\right)$ & 0.95 & $209.08{ }^{\circ} \mathrm{C}$ \\
Time $\left(X_{2}\right)$ & 0.84 & $47.60 \mathrm{~min}$ \\
Ethanol-water ratio $\left(X_{3}\right)$ & -1.29 & $24.2 \%$ \\
\hline
\end{tabular}

pre-treatment operation which is in agreement with the work of Nanssou et al. [21]; Kanchanalai et al. [36]; Amendola et al. [37] and Brosse et al. [38]. Indeed, temperature is the only one of the three factors whose increase contributes favourably to the extraction of RS and pentoses, even if this positive contribution is significant on RS and not significant on pentoses. This is explained by the fact that the increase in temperature during the pretreatment operation firstly weakens the lignocellulosic structure of the substrate (wood). It also causes an increase in the kinetic 


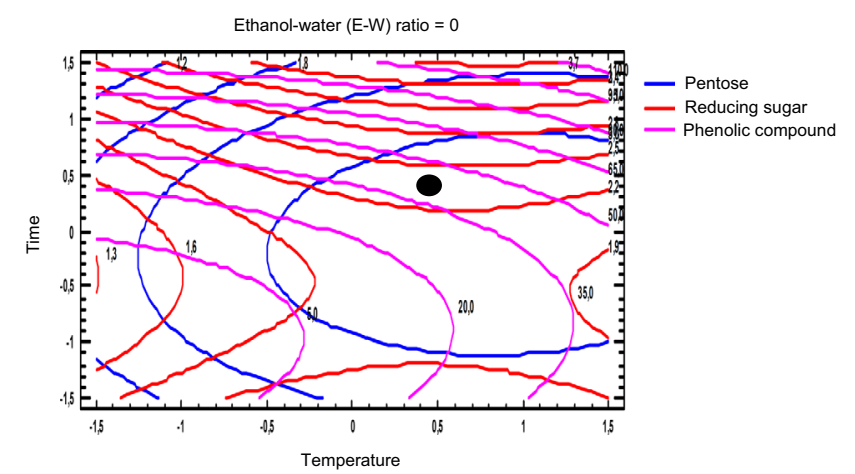

Fig. 7. Contours of response surfaces of pentoses, reducing sugars and phenolic compounds for temperature and time $(\mathrm{E}-\mathrm{W}$ ratio $=0)$.

energy of water molecule which is the majority constituent of the solvent (ethanol-water ratio). Under these conditions, the heated water molecule, which is now lighter and more fluid, easily diffuses within the lignocellulosic structure where it self-ionizes by releasing the hydronium ions. The lignocellulosic structure of sawdust from Ayous then undergoes hydrolysis reactions under the catalytic action of hydronium ions generated by the auto ionization of water [39]. The objective being to have the pentoses and the reducing sugars in good condition, it is obvious that at higher temperature, cellulosic molecules will be denatured. This is certainly what justifies the small plateau observed in $X_{1}$ in Figures 1 and 3. These curvatures (plateau) materialize the drop-in extraction rates of pentoses and reducing sugars due to the denaturation of these compounds caused by temperatures above the necessary temperatures $[37,38]$.

Time was presented as the second factor influencing the extraction of pentoses and RS. However, beyond a specific time of the pre-treatment operation, the quantities of pentoses and RS decrease in the reactor. The decrease of these compounds after these precise pre-treatment times would be due to their destruction (denaturation) by the excessively high temperature prevailing in the reactor. In fact, pentoses and reducing sugars are more sensitive to heat than their respective substrates from which they come (hemicelluloses and celluloses). They will therefore be denatured when they are exposed for longer than expected to a temperature higher than the temperature necessary for the hydrolysis of their respective substrates. So, it is quite possible to effectively carry out the pre-treatment operation in a very short time, provided that the operation takes place at the temperature considered to be optimal according to the objectives set. This is also the reason why Figures 1 and 4 show that after a specific time, the extraction rates of pentoses and reducing sugars decreases. If temperature and pre-treatment time are two important factors for the extractions of pentoses and $\mathrm{RS}$, the ethanol-water ratio is less so far as its presence in the pretreatment reactor promotes the delignification of sawdust from Ayous into preserving the lignin and the products formed [16, 17].

\subsubsection{Effect of factors on the extraction of phenolic compounds}

Alternatively, another objective was to find out the conditions necessary for the minimal extraction of Phenolic Compounds (PC) during the pre-treatment of Ayous sawdust by the organosolv method. Analysis of the mathematical model having for response the extraction of PC shows that each factor has a significant importance on the maximum extraction of $\mathrm{PC}$ during the pre-treatment operation. Considering for example the direct effect of temperature, it emerges as much from Table 4 as from Figures 5 and 6 that an increase in temperature significantly favours the extraction of PC contained in sawdust from Ayous during organosolv pre-treatment. This resonance is logical so far as, lignin is a polymer made up of aromatic units of phenolic type. These units are connected together by $\alpha$-o-aryl and $\beta$-o-aryl ether bonds and bonds between carbon atoms. The hydrolysis of the lignin fraction is the rupture of the ether bonds during the rise in temperature. This rise in temperature is accompanied by a decrease in the aliphatic hydroxyls of lignin. This last observation is probably due to two simultaneous reactions. The first is an elimination reaction by acid catalysis of the side chains with production of phenolic hydroxyls originating from the cleavage of aryl ether bonds. The rise in temperature also causes the acidification of the medium, which has a hydrolytic effect on the $\alpha$-ether bonds. If the $\alpha$-ether bonds are easily hydrolysable, the $\beta$-ether bonds are less and require a more acidic medium. Hence, the need to further increase the temperature which has a favourable effect on the acidification of the environment. So, whatever the raw material, temperature is the main factor that generates the release of phenolic compounds in the environment [21]. If a plateau has not been observed on the shape of $X_{1}$ in Figure 5, it is precisely because the extraction of $\mathrm{PC}$ which are products of the lignin hydrolysis requires a higher temperature than that necessary for the hydrolysis of celluloses and hemicelluloses.

The direct effect of time on the significant extraction of $\mathrm{PC}$ is explained by the fact that the acidity of the medium which is mainly released by hemicellulose increases with the time of pre-treatment. So, the longer the pre-treatment, the more the acid is produced in the medium, which favours both the hydrolysis of $\alpha$-ether bonds and the hydrolysis of $\beta$-ether bonds with release of PC [39].

The $\mathrm{E}-\mathrm{W}$ ratio also has a directly positive effect on the extraction of PC. This positive effect is justified by the fact that ethanol acts as a catalyst in the process of hydrolysis of the $\alpha$-aryl and $\beta$-aryl bonds which bind lignin to cellulose. Ethanol also protects the PC from the extraction during the pre-treatment operation [37, 38]. So, by increasing the concentration of ethanol in the medium, it makes sense that the extraction of $\mathrm{PC}$ is optimal $[16,17]$. However, the catalytic action of ethanol means is not a limiting factor for the extraction of PC. This means that the extraction of $\mathrm{PC}$ through the hydrolysis of these $\alpha$-aryl and $\beta$-aryl bonds would still be effective under the action of water at high temperature if there were no ethanol in the middle. And in this precise context, this work would directly achieve its objectives which are to minimize the extraction of $\mathrm{PC}$ and optimize those of pentoses and RS by simply reducing 
the pre-treatment time as suggested in Figures 1 and 3. But since ethanol also has the role of protecting the lignin which is extracted during the pre-treatment operation, the introduction of ethanol at low concentration into the medium is perfectly in accordance with the requirements of Figures 1 and 4 for the maximum production of pentoses and RS.

\subsection{Optimal point results}

The optimal multi-response points would allow during pretreatment of Ayous sawdust by the organosolv method to extract $5.12 \mathrm{mg} / \mathrm{mL}$ in pentoses, $2.29 \mathrm{mg} / \mathrm{mL}$ in Reducing Sugars (RS) and $48.77 \mathrm{mg} / \mathrm{mL}$ in Phenolic Compounds (PC). These values are lower than the values obtained after implementation of the optimal points of the three factors taken individually $(7.09 \mathrm{mg} / \mathrm{mL}$ of pentoses, $4.09 \mathrm{mg} / \mathrm{mL}$ of RS and $49 \mu \mathrm{g} / \mathrm{mL}$ of PC) in the laboratory. This difference is explained by the fact that the multi-response surface (Fig. 7) represented in two dimensions, neglects the ethanol-water ratio. Indeed, it was previously shown that the ethanol concentration ( $\mathrm{E}-\mathrm{W}$ ratio) was more important for the extraction of PC than for pentoses and RS. So, the absence of ethanol in the pre-treatment reactor prevents neither the extraction of pentoses and RS, nor the delignification of the lignocellulosic complex of Ayous sawdust. However, Figures 2a, 2b, 4a, 4b already show that ethanol still contributes, although only slightly, to the extraction of pentoses and RS. Therefore, it is obvious that its absence in the reactor justifies the decrease in the extraction of pentoses, RS and even PC observed, when the optimal multi-response points are applied. This would be a good compromise since the extraction of $\mathrm{PC}$ would decrease in all cases from $49 \mu \mathrm{g} / \mathrm{mL}$ to $48.77 \mu \mathrm{g} / \mathrm{mL}$. This result is similar to that obtained by Mesa et al. [13] who have optimized the pre-treatment with the organosolv method of bagasses of sugarcane and Wildschut et al. [15]. This reassures the effectiveness of the organosolv process for the delignification of lignocellulosic biomasses [40, 41].

\section{Conclusion}

The objective of this work was to optimize the pre-treatment of sawdust from Ayous (Triplochiton scleroxylon) by the organosolv process in order to produce bioethanol. It turns out that temperature is the most important factor in the organosolv pre-treatment process applied to sawdust from Ayous. During the pre-treatment, there is an optimal time beyond which the extraction of phenolic compounds is favoured at the expense of the extractions of pentoses and reducing sugars. What is interesting in the main objective of the pre-treatment is not to extract a maximum of phenolic compounds, but rather to break the $\alpha$-aryl and $\beta$-aryl bonds which bind lignin to cellulose. This is perfectly feasible by manipulating the temperature and pre-treatment time factors. Finally, the ethanol-water ratio which expresses the amount of ethanol necessary for the extraction of phenolic compounds is not a limiting factor in the success of the operation of pre-treatment of Ayous sawdust by the organosolv method. This work shows that organosolv pre-treatment is an effective method of delignification of the lignocellulosic structure of Ayous sawdust. The optimal conditions for the pre-treatment operation having been defined, it is also important to find the optimal conditions for enzymatic hydrolysis to have an optimal yield of bioethanol after the production process of this biofuel based on sawdust from Triplochiton scleroxylon.

Acknowledgments. The authors of this work address their gratitude to Prof. Emmanuel Nso, Head of Department of Process Engineering, National advanced School of Agro-Industrial Sciences of Ngaoundéré. Our thanks also go to Bernie Tchouanti Nzali, doctoral thesis student in Department of Process Engineering and Asongazi Njuaka Isidore, future engineer of ENSAI at the University of Ngaounéré for his participation in the review of this article.

\section{Supplementary Materials}

The supplementary material of this article is available at https://ogst.ifpenergiesnouvelles.fr/10.2516/ogst/2021004/ olm.

Table S1: Physico-chemical composition of Ayous sawdust (Triplochiton scleroxylon).

\section{References}

1 Mintyene B.J. (2010) Commerce de bois légal: politiques publiques et privées "L'expérience au Cameroun », s.n., Douala, p. 20.

2 Kamkuimo P., Ayouba S., Mbarga A. (2018) Étude sur la situation de référence de valorisation des rebuts de l'exploitation forestière et de scierie dans la région de l'Est-Cameroun, ASD. https://www.academia.edu/download/58307181/Rapport_ etude de reference valorisation rebuts Est Cameroun_-2018.pdf.

3 Samomssa I., Nono Y.J., Tsamo C., Dinica M.R., Kamga R. (2019) Influence of physico-chemical parameters on fuel briquettes properties formulated with mixture of biomasses, J. Env. Sci. Pollut. Res. 5, 2, 338-341. https://doi.org/ 10.30799/jespr.165.19050202.

4 Yaser A.Z., Rahman R.A., Kalil M.S. (2007) Co-composting of palm oil mill sludge-sawdust, Pak. J. Biol. Sci. 10, 44734478. https://doi.org/10.3923/pjbs.2007.4473.4478.

5 Oguntoke O., Otusanya O.K., Annegarn H.J. (2013) Emission of pollutants from wood waste incineration at sawmills in Abeokuta metropolis, Nigeria Int. J. Env. Stud. 70, 6, 964-975. https://doi.org/10.1080/00207233.2013.845709.

6 United Nations, Department of Economic and Social Affairs, Population Division. 2019. World Population Prospects 2019: Highlights, 17 June 2019. https://www.un.org/development/desa/publications/world-population-prospects-2019highlights.html

7 WEO (World Energy Outlook) (2019) Rapport de l'Agence Internationale de l'énergie (AIE), https://www.iea.org/ reports/world-energy-outlook-2019.

8 Yang B., Dai Z., Ding S., Wyman C.E. (2011) Enzymatic hydrolysis of cellulosic biomass, Biofuels 2, 4, 421-450. https://doi.org/10.4155/bfs.11.116. 
9 Doyon M., Mondon M., Mondor S. (2011) Impacts du developpement des biocaburants de seconde génération sur le marché des matières residuelles, CIRANO, Montréal.

10 Nzali B.T., Mvogo P.O., Ali A., Mouangue R. (2019) Effect of particle size on syngas production using sawdust of Cameroonian Triplochiton scleroxylon, Scientific African 6, e00182. https://doi.org/10.1016/j.sciaf.2019.e00182.

11 Gollakota A.R.K., Kishore N., Gu S. (2017) A review on hydrothermal liquefaction of biomass, Renew. Sust. Energ. Rev., 81, 1378-1392. https://doi.org/10.1016/j.rser.2017.05.178.

12 Toor S.S., Rosendahl L., Rudolf A. (2011) Hydrothermal liquefaction of biomass: A review of subcritical water technologies, Energy 36, 2328-2342. https://doi:10.1016/j. energy.2011.03.013.

13 Mesa L., González E., Cara C., González M., Castro E., Mussatto S.I. (2011) The effect of organosolv pretreatment variables on enzymatic hydrolysis of sugarcane bagasse, Chem. Eng. J. 168, 3, 1157-1162. https://doi:10.1016/j. cej.2011.02.003.

14 Ogier J.C., Leygue J.P., Ballerini D., Pourquie J., Rigal L. (1999) Production d'éthanol à partir de biomasse lignocellulosique, Oil Gas Sci. Technol. - Rev. IFP Energies nouvelles 54, 1, 67-94. https://doi.org/10.2516/ogst:1999004.

15 Wildschut J., Smit A.T., Reith J.H., Huijgen W.J. (2013) Ethanol-based organosolv fractionation of wheat straw for the production of lignin and enzymatically digestible cellulose, Bioresour. Technol. 135, 58-66. https://doi.org/ 10.1016/j.biortech.2012.10.050.

16 Zhao X., Li S., Wu R., Liu D. (2017) Organosolv fractionating pre-treatment of lignocellulosic biomass for efficient enzymatic saccharification: chemistry, kinetics, and substrate structures, Biofuel. Bioprod. Bioref. 11, 567-590. https://doi.org/10.1002/bbb.1768.

17 Zhou Z., Lei F., Li P., Jiang J. (2018) Lignocellulosic biomass to biofuels and biochemicals, a comprehensive review with a focus on ethanol organosolv pretreatment technology, Biotech. Bioeng., 115, 2683-2702. https://doi.org/10.1002/ bit.26788.

18 Demirbas A. (2008) Biofuels sources, biofuel policy, biofuel economy and global biofuel projections, Energy Convers. Manage. 49, 8, 2106-2116. https://doi.org/10.1016/j. enconman.2008.02.020.

19 Boussarsar H. (2008) Application de traitements thermique et enzymatique de solubilisation et saccharification de la fraction hemicellulosique en vue de la valorisation de la bagasse de canne à sucre. Thèse de doctorat en Chimie physique industrielle et génie biologique, Soutenue en 2008 à Reims en cotutelle avec l'Université de Sfax. 201p. http:// www.theses.fr/2008REIMS019.

20 Fan T.L., Lee Y.H., Gharpuray M.M. (1982) The nature of lignocellulosics and their pretreatments for enzymatic hydrolysis, Microbial reactions, Springer, Berlin, Heidelberg, pp. 157-187.

21 Nanssou P.A.K., Nono Y.J., Kapseu C. (2016) Pretreatment of cassava stems and peelings by thermohydrolysis to enhance hydrolysis yield of cellulose in bioethanol production process, Renew. Energ. 97, 252-265. https://doi.org/ 10.1016/j.renene.2016.05.050.

22 Van Soest P., Robertson J. (1985) Analysis of forages and fibrous foods, Department of Animal Science, Cornell University, Ithaca, NY, USA.

23 Klason P. (1908) Chemical composition of deal (Fir wood), Ark. Kemi. Mineral. Geol. 3, 1-10.
24 N'Diaye S., Rigal L., Larocque P., Vidal P.F. (1996) Extraction of hemicelluloses from poplar, Populus tremuloides, using an extruder-type twin-screw reactor: a feasibility study, Bioresour. Technol. 57, 1, 61-67. https://doi.org/ 10.1016/0960-8524(96)00041-7.

25 Godin B., Ghysel F., Agneessens R., Schmit T., Gofflot S., Lamaudière S., Delcarte J. (2010) Détermination de la cellulose, des hémicelluloses, de la lignine et des cendres dans diverses cultures lignocellulosiques dédiées à la production de bioéthanol de deuxième génération|Cellulose, hemicelluloses, lignin, and ash contents in various lignocellulosic crops for second generation bioethanol production], BASE 14, 549. https://popups.uliege.be/1780-4507/index.php? $i d=6186$.

26 Park N., Kim Y.H., Koo B.W., Yeo H., Choi I.G. (2010) Organosolv pretreatment with various catalysts for enhancing enzymatic, Bioresour. Technol., 101, 18, 7057-7064. https://doi.org/10.1016/j.biortech.2010.04.020.

27 Carrasco R.C., Oncina J. (1994) Learning stochastic regular grammars by means of a state merging method, in: International Colloquium on Grammatical Inference, Springer, Berlin, Heidelberg, pp. 139-152. https://link.springer.com/ chapter/10.1007/3-540-58473-0_ 144.

28 Kabel M.A., Bos G., Zeevalking J., Voragen A.G., Schols H.A. (2007) Effect of pretreatment severity on xylan solubility and enzymatic breakdown of the remaining cellulose from wheat straw, Bioresour. Technol. 98, 10, 2034-2042. https://doi.org/10.1016/j.biortech.2006.08.006.

29 Pan X., Arato C., Gilkes N., Gregg D., Mabee W., Pye K., Saddler J. (2005) Biorefining of softwoods using ethanol organosolv pulping: Preliminary evaluation of process streams for manufacture of fuel-grade ethanol and co-products, Biotechnol. Bioeng. 90, 4, 473-481. https: //doi.org/10.1002/bit.21883.

30 Joglekar A.M., May A.T. (1987) Product excellence through design of experiments, Cereal Foods World 32, 12, 857.

31 Baş D., Boyacı İ.H. (2007) Modeling and optimization I: Usability of response surface methodology, J. Food Eng. 78, 3, 836-845. https://doi.org/10.1016/j.jfoodeng.2005.11.024.

32 Dalgaard P., Jørgensen L.V. (1998) Predicted and observed growth of Listeria monocytogenes in seafood challenge tests and in naturally contaminated cold-smoked salmon, Int. J. Food Microbiol. 40, 1, 105-115. https://doi.org/10.1016/ S0168-1605(98)00019-1.

33 Fisher E.H., Stein E.A. (1961) DNS colorimetric determination of available carbohydrates in foods, Biochem. Prep. 8, 30-37.

34 Akpinar O., Serdal S., Okan L., Abdulvahit S. (2012) Evaluation of antioxidant activity of dilute acid hydrolysate of wheat straw during xylose production, Ind. Crops Prod. 40, 39-44. https://doi.org/10.1016/j.indcrop.2012.02.035.

35 Hashimoto S., Shogren M.D., Pomeranz Y. (1987) Cereal pentosans: their estimation and significance. I. Pentosans in wheat and milled wheat products, Cereal Chem. 64, 1, 30-34.

36 Kanchanalai P., Temani G., Kawajiri Y., Realff M.J. (2016) Reaction kinetics of concentrated-acid hydrolysis for cellulose and hemicellulose and effect of crystallinity, BioResources 11, 1, 1672-1689. https://ojs.cnr.ncsu.edu/index. $\mathrm{php} /$ BioRes/article/view/BioRes.

37 Amendola D., De Faveri D.M., Egües I., Serrano L., Labidi J., Spigno G. (2012) Autohydrolysis and organosolv process for recovery of hemicelluloses, phenolic compounds and lignin from grape stalks, Bioresour. Technol. 107, 267-274. https://doi.org/10.1016/j.biortech.2011.12.108. 
38 Brosse N., Sannigrahi P., Ragauskas A. (2009) Pretreatment of Miscanthus $x$ giganteus using the ethanol organosolv process for ethanol production, Ind. Eng. Chem. Res. 48, 8328-8334. https://doi.org/10.1021/ie9006672.

39 Babier G. (2010) Relation structure/réactivité en conversion hydrothermale des macromolécules de lignocelluloses, ICMCB - Institut de Chimie de la Matière Condensée de Bordeaux. https://tel.archives-ouvertes.fr/tel-00562111
40 Paszner L., Cho H.J. (1989) Organosolv pulping: acidic catalysis options and their effect on fiber quality and delignification, Tappi J. 72, 2, 135-142. https://doi.org/ 10.1016/j.indcrop.2014.11.018.

41 Vallejos M.E., Zambon M.D., Area M.C., Curvelo A.A.S. (2015) Low liquid-solid ratio fractionation of sugarcane bagasse by hot water autohydrolysis and organosolv delignification, Ind. Crops Prod. 65, 349-353. https://doi.org/ 10.1016/j.indcrop.2014.11.018. 